\title{
The Precision of Unconditional Estimators of the Equity Premium
}

\author{
Samih Antoine Azar ${ }^{1}$ \\ ${ }^{1}$ Faculty of Business Administration \& Economics, Haigazian University, Beirut, Lebanon \\ Correspondence: Samih Antoine Azar, Professor, Faculty of Business Administration \& Economics, Haigazian \\ University, Mexique Street, Kantari, Beirut, Lebanon. Tel/fax: 961-134-9230. E-mail: samih.azar@haigazian.edu.lb \\ Received: December 22, 2014 \\ Accepted: January 13, 2015 \\ Online Published: January 14, 2015 \\ doi:10.5430/afr.v4n1p143 \\ URL: http://dx.doi.org/10.5430/afr.v4n1p143
}

\begin{abstract}
This paper has the purpose of providing unconditional estimators of the equity premium. In plain words the estimators are obtained by the constants in regressions of the equity premium on a constant. More than one specification is tried and more than one type of standard errors is implemented. The specifications include ordinary least squares, EGARCH, robust least squares, quantile regressions, and Markov switching regressions with two regimes. The analysis is repeated by adding in categorical variables that correspond to outliers. Theoretically these estimators of the equity premium are unbiased and consistent. All models are subjected to serial correlation tests on the residuals. These tests support the absence of serial correlation. This is conducive to the conclusion that the models are well specified and that the estimators are not only unbiased and consistent but also efficient. The paper gives point estimates and $95 \%$ confidence intervals of the equity premium, develops hypothesis tests, and reports point estimates of the standard errors. The results may help in assessing the magnitude of the equity premium and the precision with which this premium is measured.
\end{abstract}

Keywords: Equity premium, Unconditional estimators, Robust standard errors, EGARCH, Ordinary least squares, Robust least squares, Quantile regressions, Markov switching regressions, Categorical outlier variables

\section{Introduction}

The size of the equity risk premium has been the subject of intense investigation. Based on this research it is inferred that the equity premium is surely much larger than the short term T-bill rate. What is lacking in the literature is the extent of precision in estimating the equity premium. Rare are the studies that provide a standard error for the estimated equity premium. Dimson et al. (2008) are an exception. Other academicians, like Fama and French (2002) and Goetzmann and Ibbotson (2006), report point estimates and standard deviations from which it is difficult to derive standard errors. This paper finds that these standard errors are relatively large. Thus the major purpose of this paper is to offer as many precision estimates as possible by varying the model that is specified, while keeping these models simple. Two unbiased estimators of the equity premium are the unconditional mean and the unconditional median. The latter estimator is a natural input in quantile regressions. The first unconditional estimator can be obtained easily from a regression of the premium on a constant, and the precision of estimation is the precision with which this constant is estimated. More than one variant of this basic model is attempted. There is more disparity than commonness in the results. Especially crucial is whether or not the standard errors need to be adjusted for serial correlation and heteroscedasticity. Robust standard errors tend to produce larger standard errors, and consequently less precision. In addition each variant specification provides for a point estimate of the equity premium that is generally different from other specifications. This paper intends to provide for the equity premium (1) point estimates with their respective t-statistics, (2) 95\% confidence interval estimates, and (3) the appropriate standard errors. Of course a large standard error does not necessarily mean that precision is lost because some point estimates are larger than others. Surprisingly some interval confidence limits include negative realizations for the equity premium. This means that the hypothesis that the equity premium is in all cases and always positive may turn out to be untenable.

The specifications that are selected are the following. First, regressions on the constant with HAC standard errors are conducted by calculating robust standard errors (Newey and West, 1987). Then an EGARCH (Nelson, 1991) model of the conditional variance is estimated with the assumption of a t-distribution. The mean equation includes only the constant. Then robust least squares are tried with three types of robust standard errors. Then quantile regressions are implemented at the median of the series. And finally three variants of Markov switching regressions with two regimes are applied. One of the two regimes is selected. The estimation is repeated with the inclusion of the 7 categorical variables that identify the 7 outliers in the data. The same specifications are repeated except for the EGARCH model which turns out to be inapplicable. This last battery of regressions is not properly unconditional 
because these regressions are effectively conditional on the selected dummy variables. However the fact that only dummy variables are included makes the models to approach closely an unconditional regression.

The paper is organized as follows. In the next section, section 2, some theoretical issues pertaining to the equity risk premium are covered. Section 3 is the empirical part where the regression results are presented and discussed. The last section is a conclusion.

\section{Theory}

The paradigm in the literature up until the late 1970s was that equities must earn higher returns than a safe asset, like a T-bill, as compensation for the additional systematic risk. The CAPM was at that time still the rule. Little interest was expressed on how large the equity premium is or should be. Concern about the size of the equity risk premium surfaced after the seminal paper by Mehra and Prescott (1985) was published. Mehra and Prescott showed that the equity premium is too large relative to theoretical expectations by building upon an appraised study by Lucas (1978). In fact they find that the coefficient of relative risk aversion needed to justify the equity premium must be as high as 50 , which is unreasonable. A whole literature has emerged in order to explain this discrepancy or puzzle. The papers in the edited volume of Mehra (2008) are testimony to the richness of this literature. It is not the purpose of this paper to summarize the various theoretical efforts that have been made to reconcile theory with fact and to resolve the underlying puzzle. Let it be mentioned however that Weil (1989) transforms the puzzle of a too great actual equity premium to a puzzle of a too great theoretical risk-free rate.

Instead of trying to find out theoretical vindications for the puzzle some authors resorted to different agendas, like that of providing evidence that the expected, or normal, or theoretical, equity premium is less than the actual premium. See, for example, Arnott and Bernstein (2002), Fama and French, (2002), and Bostock (2004). However, by surveying the profession, Welch (2000) finds that financial economists estimate the just equity premium to be close to the actual one.

More recent research on estimating the equity premium has taken an accounting route. The basic model is the residual income model of Ohlson (1995), which relates the market value of equity to the sum of the book value of equity with the discounted future residual income. Easton et al. (2002) and Easton (2004) extend this basic Ohlson model to estimate simultaneously the cost of equity and the long term growth rate that occurs after the terminal date of the earnings forecast by financial analysts. This allows these authors to derive a simple linear regression equation in which the coefficients provide simultaneously estimates of the two target parameters, i.e. the cost of equity and the long run growth rate in earnings. The estimates of the cost of equity are averaged to obtain the aggregate equity premium. Nekrasov and Ogneva (2011) further refine the model of Easton et al. (2002) and Easton (2004) by showing that weighted least squares provide better individual and overall estimates. Fitzgerald et al. (2013) use similar equity valuation models and they simulate key variables. They take 3,012 alternative combinations of these variables and they plug these values into the valuation model. Fitzgerald et al. (2013) call their estimates unconstrained because "they are not constrained by the researchers' growth rate assumption or by the assumption that all firms carrying the same industry label have identical cost of capital and growth estimates, and they are not constrained by the conversion of a discounted cash flow model to a linear form" (p.563). All these studies start by estimating the cost of equity for individual or for small portfolios and they aggregate these estimates to obtain the market equity premium. Unfortunately all the estimates remain still point estimates since the researchers fail to provide a measure of precision to their estimates. This paper has the essential purpose of filling this gap.

According to the Arbitrage Pricing Theory (APT), due to Ross (1976), the return on any financial asset is explained by a reaction to unexpected shocks, mostly macroeconomic in nature. If $\widetilde{r}_{i t}$ is the stochastic return on a financial asset $i$, and $\varepsilon_{i t}$ is an unexpected unsystematic or idiosyncratic shock with mean zero, $E_{t}\left(\varepsilon_{i t}\right)=0$ for each $i$, then the following is true through time $t$ :

$$
\widetilde{r}_{i t}=\bar{r}_{i}+\sum \beta_{j} \widetilde{X}_{j i t}+\varepsilon_{i t} \text { with } E_{t}\left(\widetilde{X}_{j i t}\right)=0 \quad \forall j \text { and } i \Rightarrow E_{t}\left(\widetilde{r}_{i t}\right)=E_{t}\left(\bar{r}_{i}\right)=\mu_{i}
$$

The same applies to a return on a market index, and, additionally, to the market premium, which is the market return over the return on the risk-less asset. The thrust of this paper is to undertake variants of regressions on a constant, which represents $\bar{r}_{i}$ in equation (1). As demonstrated to the right-hand side of equation (1) this constant is an unbiased and consistent, but inefficient, estimator of the population mean return $\mu_{i}$. The t-statistic on this constant is equivalent to a t-test on a measure of location with the following actual test statistic:

$$
\text { actual } t \text {-statistic }=\frac{\bar{x}-c}{s} \sqrt{n}
$$

where $\bar{x}$ is the sample mean, or any other measure of location, $s$ is the sample standard deviation, and $n$ is the sample size. In all tests the parameter $\mathrm{c}$ is taken to be zero. In regressions on a constant the sample standard error on 
this constant is overstated, because of omitted variables, (see equation (1), which makes a $95 \%$ confidence interval an interval with more than $95 \%$ confidence. In most cases the measure of location is the mean but in the case of the quantile regressions this measure is the median. If the distribution is symmetric the mean and the median should be quite adjacent to each other. Otherwise the results may differ, and they actually do. Two series for the equity premium are considered, one calculated from the arithmetic percentage change, and the other from the geometric formulae. The first series of the equity premium has a skewness of -0.428994 , and the second series has a skewness of -0.661412 . The tests for skewness produce the following two test statistics respectively -4.85035 and -7.47815 . These are distributed, under the null hypothesis, as a standard normal distribution. The null of symmetry is rejected for both series at low marginal significance levels. Hence there is strong evidence for negative skewness. The latter implies that the average lies to the left of the median. In quantile regressions, based on the median, the point estimates of the equity premium are larger but this comes at the expense of precision as the standard errors are also larger. The same issue arises with Markov switching regressions which provide relatively high point estimates that are coupled with large standard errors.

\section{Empirical results}

The data on the S\&P 500 stock market index is obtained from the web page of EconStats. The data on the T-bill rate of return in the secondary market is retrieved from the web page of the Federal Reserve Bank of Saint Louis. The data is monthly and spans the period from early March 1950 to early January 2014, with 767 observations on each variable. Two variable series for the equity premium are computed: the arithmetic return on the S\&P 500 from which the T-bill rate is deducted, and the geometric return of the S\&P 500 from which the T-bill rate is subtracted. The geometric rate is just the first difference in the natural logs of the level series of the S\&P 500. If the series are independently and identically distributed the average of the second estimate must be lower than that of the first by half the variance of the first. The standard deviation of the equity returns is $20 \%$ on average, and as a result the variance is $4 \%$, then one half of this variance is $2 \%$. It is therefore expected that the second measure of the equity premium be smaller from the first by around $2 \%$. Unfortunately the empirical results do not obey to this requirement.

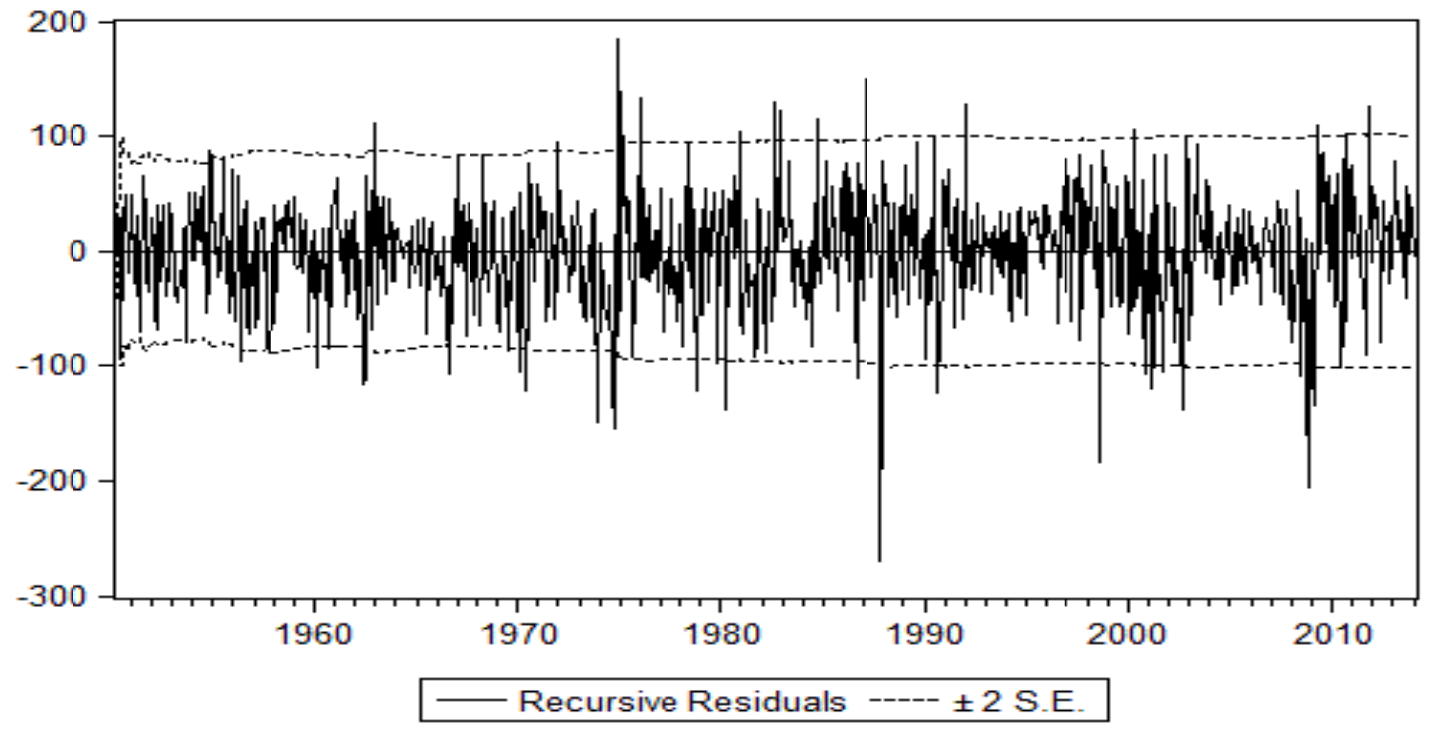

There are two general sets of estimation. The first set is by regressing the equity premium plainly on a constant, and the second is by including in the regression, besides the constant, 7 dummy variables representing the 7 outliers in the sample. These outliers are identified by inspecting the recursive residuals of the least squares regression on a constant. If the realized residual falls outside the band of plus or minus two standard errors then it is considered to be an outlier. The graph is exhibited just above. The seven outliers are on the early days of December 1973, October 1974, November 1974, February 1987, November 1987, September 1998, and November 2008.

In Table 1 the empirical results of nine variants of regressions on a constant are presented. Table 2 repeats the same regressions, except for the EGARCH model, by including in the estimation the seven dummies. The nine variants of the regressions in Table 1 are as follows. First regressions on the constant with HAC standard errors are conducted by calculating robust standard errors according to Newey and West (1987). Then an EGARCH (Nelson, 1991) model 
of the conditional variance is estimated with the additional assumption of a t-distribution. The mean equation includes only the constant. Then robust least squares are tried which adjust the regressions for outliers in the dependent variable, and these are estimated with three different types of robust standard errors (Huber, 1973, 1981). Then quantile regressions are implemented at the median of the series (Koenker and Basset, 1978; Basset and Koenker, 1982; Koenker, 1994; Koenker and Machado, 1999; and Koenker, 2005). And finally Markov switching regressions with two regimes are applied (Goldfeld and Quandt, 1973, 1976; Maddala, 1986; Hamilton, 1990, 1994; Frühwirth-Schnatter, 2006). One of the two regimes is selected. These switching regressions are carried out with the assumption of constant variances across regimes or with the assumption of different variances across regimes and finally with the use of robust standard errors together with regime-specific variances. All these specifications are repeated, except for the EGARCH model, with the inclusion of the 7 categorical variables that identify the 7 outliers in the data, making eight regressions in total instead of nine. In addition Tables 1 and 2 present regressions results with the two methods of the calculation of the return of the S\&P 500 that is part of the equity premium, and which are by arithmetic returns and geometric returns.

Table 1. Plain regressions on the constant.

\begin{tabular}{|c|c|c|c|c|c|c|}
\hline \multirow[b]{2}{*}{ specification } & \multicolumn{3}{|c|}{$1200 *\left(\left(s p 500_{t}-s p 500_{t-1}\right) / s p 500_{t-1}\right)-T B 3$} & \multicolumn{3}{|c|}{$1200 *\left(L N\left(s p 500_{t} / s p 500_{t-1}\right)\right)-T B 3$} \\
\hline & $\begin{array}{c}\text { Point } \\
\text { estimate }\end{array}$ & $\begin{array}{l}\text { Interval } \\
\text { estimate }\end{array}$ & $\begin{array}{c}\text { Standard } \\
\text { error }\end{array}$ & $\begin{array}{l}\text { Point } \\
\text { estimate }\end{array}$ & $\begin{array}{l}\text { Interval } \\
\text { estimate }\end{array}$ & $\begin{array}{c}\text { Standard } \\
\text { error }\end{array}$ \\
\hline $\begin{array}{l}\text { Unconditional mean with HAC } \\
\text { standard errors }\end{array}$ & $\begin{array}{c}3.886473 \\
(1.887173)\end{array}$ & $\begin{array}{c}-0.1500 \\
7.9229\end{array}$ & 2.0594 & $\begin{array}{c}2.808065 \\
(1.345143)\end{array}$ & $\begin{array}{c}-1.2836 \\
6.8997\end{array}$ & 2.0876 \\
\hline $\begin{array}{l}\text { EGARCH with } \\
\text { t-distribution }\end{array}$ & $\begin{array}{c}5.172633 \\
(3.188129)\end{array}$ & $\begin{array}{l}1.9926 \\
8.3527\end{array}$ & 1.6225 & $\begin{array}{l}4.821491 \\
(2.973561)\end{array}$ & $\begin{array}{l}1.6434 \\
7.9995\end{array}$ & 1.6215 \\
\hline $\begin{array}{l}\text { Robust least squares } \\
\text { with M-estimation } \\
\text { (Huber Type I) }\end{array}$ & $\begin{array}{c}5.529527 \\
(3.167230)\end{array}$ & $\begin{array}{l}2.1076 \\
8.9514\end{array}$ & 1.7459 & $\begin{array}{c}5.232251 \\
(3.022204)\end{array}$ & $\begin{array}{l}1.8390 \\
8.6255\end{array}$ & 1.7313 \\
\hline $\begin{array}{l}\text { Robust least squares } \\
\text { with M-estimation } \\
\text { (Huber Type II) }\end{array}$ & $\begin{array}{c}5.529527 \\
(3.167680)\end{array}$ & $\begin{array}{l}2.1081 \\
8.9509\end{array}$ & 1.7456 & $\begin{array}{c}5.232251 \\
(3.022643)\end{array}$ & $\begin{array}{l}1.8395 \\
8.6250\end{array}$ & 1.7310 \\
\hline $\begin{array}{l}\text { Robust least squares } \\
\text { with M-estimation } \\
\text { (Huber Type III) }\end{array}$ & $\begin{array}{c}5.529527 \\
(3.168580)\end{array}$ & $\begin{array}{l}2.1091 \\
8.9499\end{array}$ & 1.7451 & $\begin{array}{c}5.232251 \\
(3.023520)\end{array}$ & $\begin{array}{l}1.8404 \\
8.6241\end{array}$ & 1.7305 \\
\hline $\begin{array}{l}\text { Quantile regression } \\
\text { (Median) }\end{array}$ & $\begin{array}{c}7.105946 \\
(3.297307)\end{array}$ & $\begin{array}{c}2.8820 \\
11.3299\end{array}$ & 2.1551 & $\begin{array}{c}7.046581 \\
(3.299172)\end{array}$ & $\begin{array}{c}2.8603 \\
11.2329\end{array}$ & 2.1359 \\
\hline $\begin{array}{l}\text { Markov switching } \\
\text { (same variances) }\end{array}$ & $\begin{array}{c}8.508014 \\
(4.062184)\end{array}$ & $\begin{array}{c}4.4661 \\
12.5499\end{array}$ & 2.0622 & $\begin{array}{c}8.028245 \\
(4.072284)\end{array}$ & $\begin{array}{c}4.1642 \\
11.8923\end{array}$ & 1.9714 \\
\hline $\begin{array}{l}\text { Markov switching } \\
\text { (different variances) }\end{array}$ & $\begin{array}{c}9.161637 \\
(4.104289)\end{array}$ & $\begin{array}{c}4.7865 \\
13.5368\end{array}$ & 2.2322 & $\begin{array}{c}9.283084 \\
(4.473359)\end{array}$ & $\begin{array}{c}5.2157 \\
13.3505\end{array}$ & 2.0752 \\
\hline $\begin{array}{c}\text { Markov switching } \\
\text { (different variances with } \\
\text { Huber-White robust standard } \\
\text { errors) }\end{array}$ & $\begin{array}{c}9.161637 \\
(3.192338)\end{array}$ & $\begin{array}{c}3.5367 \\
14.7866\end{array}$ & 2.8699 & $\begin{array}{l}9.283084 \\
(3.825005)\end{array}$ & $\begin{array}{c}4.5263 \\
14.0399\end{array}$ & 2.4269 \\
\hline
\end{tabular}

Notes: In parentheses are t-statistics. sp500 stands for the S\&P 500 stock market index. TB3 stands for the 3-month T-bill rate in the secondary market. $L N$ is the natural logarithm. In the Markov switching regressions one of the two regimes is selected.

In Table 1, and in what concerns the equity premiums obtained from arithmetic returns of the S\&P 500, the point estimates range widely between $3.886473 \%$ and $9.161637 \%$. Whether these point estimates are plausible is an open question. All average equity premiums are statistically significantly different from zero, with the lowest t-statistic being 3.167230, except for the average obtained by HAC robust standard errors, (Newey and West, 1987), which carries a t-statistic of 1.887173 . As a consequence the $95 \%$ confidence interval of the equity premium of this last regression includes negative realizations. For the remaining eight specifications the minimum limit of the $95 \%$ confidence intervals is an annualized $1.9926 \%$, not that far from zero. However the maximum of the lowest limits of the same $95 \%$ confidence intervals is an annualized $4.7865 \%$. The maximum limit of all $95 \%$ confidence intervals is 
$14.7866 \%$, and the minimum of the upper limits of these intervals is $7.9229 \%$. There is also some variation in the standard errors. The minimum standard error is $1.6225 \%$ and the maximum is $2.8699 \%$.

In Table 1, and in what concerns the equity premiums obtained from geometric returns of the S\&P 500, the point estimates range more widely than before between $2.808065 \%$ and $9.283084 \%$. While the first estimate is lower by approximately $1 \%$ from its counterpart with arithmetic calculations, the second estimate is surprisingly higher than its arithmetic counterpart. This contradicts the expectation of a $2 \%$ lower point estimate for the statistics from geometric returns. Again whether these point estimates are plausible is an open question. All average equity premiums are statistically significantly different from zero, with the lowest t-statistic being 2.973561 , except for the average obtained by HAC robust standard errors, (Newey and West, 1987), which carries a t-statistic of 1.345143. As a consequence the $95 \%$ confidence interval of the equity premium of this last regression includes negative realizations. For the remaining eight specifications the minimum limit of the $95 \%$ confidence intervals is an annualized $1.6434 \%$, which is not that far from zero, while the maximum lower limit is $5.2157 \%$. However the maximum of the upper limits of the same $95 \%$ confidence intervals is an annualized $14.0399 \%$, while the minimum of the upper limits is $6.8997 \%$. There is also some variation in the standard errors which are, however, always less than their counterparts with arithmetic calculation of the S\&P 500 stock market returns. The minimum standard error is $1.6215 \%$ and the maximum is $2.4269 \%$. This compares with a minimum standard error of $1.6225 \%$ and a maximum of $2.8699 \%$ with the arithmetic calculation.

Table 2. Regressions on the constant including 7 dummy variables identified from the recursive residuals.

\begin{tabular}{|c|c|c|c|c|c|c|}
\hline & \multicolumn{3}{|c|}{$1200 *\left(\left(s p 500_{t}-s p 500_{t-1}\right) / s p 500_{t-1}\right)-T B 3$} & \multicolumn{3}{|c|}{$1200 *\left(L N\left(s p 500_{t} / s p 500_{t-1}\right)\right)-T B 3$} \\
\hline specification & $\begin{array}{l}\text { Point } \\
\text { estimate }\end{array}$ & $\begin{array}{l}\text { Interval } \\
\text { estimate }\end{array}$ & $\begin{array}{c}\text { Standard } \\
\text { error }\end{array}$ & $\begin{array}{c}\text { Point } \\
\text { estimate }\end{array}$ & $\begin{array}{l}\text { Interval } \\
\text { estimate }\end{array}$ & $\begin{array}{c}\text { Standard } \\
\text { error }\end{array}$ \\
\hline $\begin{array}{l}\text { Unconditional mean without } \\
\text { HAC standard errors }\end{array}$ & $\begin{array}{c}4.715104 \\
(2.751336)\end{array}$ & $\begin{array}{l}1.3562 \\
8.0740\end{array}$ & 1.7138 & $\begin{array}{l}3.769370 \\
(2.204516)\end{array}$ & $\begin{array}{l}0.4181 \\
7.1207\end{array}$ & 1.7098 \\
\hline $\begin{array}{l}\text { Robust least squares } \\
\text { With M-estimation } \\
\text { (Huber Type I) }\end{array}$ & $\begin{array}{c}5.602244 \\
(3.244004)\end{array}$ & $\begin{array}{l}2.2174 \\
8.9871\end{array}$ & 1.7270 & $\begin{array}{c}5.254334 \\
(3.063829)\end{array}$ & $\begin{array}{l}1.8930 \\
8.6156\end{array}$ & 1.7150 \\
\hline $\begin{array}{c}\text { Robust least squares } \\
\text { With M-estimation } \\
\text { (Huber Type II) }\end{array}$ & $\begin{array}{c}5.602244 \\
(3.242259)\end{array}$ & $\begin{array}{l}2.2156 \\
8.9889\end{array}$ & 1.7279 & $\begin{array}{c}5.254334 \\
(3.062259)\end{array}$ & $\begin{array}{l}1.8913 \\
8.6174\end{array}$ & 1.7158 \\
\hline $\begin{array}{l}\text { Robust least squares } \\
\text { With M-estimation } \\
\text { (Huber Type III) }\end{array}$ & $\begin{array}{c}5.602244 \\
(3.243655)\end{array}$ & $\begin{array}{l}2.2171 \\
8.9874\end{array}$ & 1.7271 & $\begin{array}{c}5.254334 \\
(3.063837)\end{array}$ & $\begin{array}{l}1.8930 \\
8.6156\end{array}$ & 1.7150 \\
\hline $\begin{array}{l}\text { Quantile regression } \\
\text { (Median) }\end{array}$ & $\begin{array}{c}7.438595 \\
(3.474467)\end{array}$ & $\begin{array}{c}3.2424 \\
11.6348\end{array}$ & 2.1409 & $\begin{array}{c}7.393170 \\
(3.484443)\end{array}$ & $\begin{array}{c}3.2345 \\
11.5518\end{array}$ & 2.1217 \\
\hline $\begin{array}{l}\text { Markov switching } \\
\text { (same variances) }\end{array}$ & $\begin{array}{c}10.99390 \\
(4.117182)\end{array}$ & $\begin{array}{c}5.7602 \\
16.2276\end{array}$ & 2.6702 & $\begin{array}{c}11.64497 \\
(4.594765)\end{array}$ & $\begin{array}{c}6.6775 \\
16.6124\end{array}$ & 2.5344 \\
\hline $\begin{array}{l}\text { Markov switching } \\
\text { (different variances) }\end{array}$ & $\begin{array}{c}9.004417 \\
(3.147815)\end{array}$ & $\begin{array}{c}3.3978 \\
14.6111\end{array}$ & 2.8605 & $\begin{array}{c}9.259777 \\
(3.329913)\end{array}$ & $\begin{array}{c}3.8094 \\
14.7101\end{array}$ & 2.7808 \\
\hline $\begin{array}{c}\text { Markov switching } \\
\text { (different variances with } \\
\text { Huber-White robust standard } \\
\text { errors) }\end{array}$ & $\begin{array}{c}9.004417 \\
(2.850117)\end{array}$ & $\begin{array}{c}2.8122 \\
15.1967\end{array}$ & 3.1593 & $\begin{array}{c}9.259777 \\
(3.000691)\end{array}$ & $\begin{array}{c}3.2114 \\
15.3081\end{array}$ & 3.0859 \\
\hline
\end{tabular}

Notes: See notes under Table 1. All regressions include 7 dummy variables. The dummies are respectively for the early days of December 1973, October 1974, November 1974, February 1987, November 1987, September 1998, and November 2008.

In Table 2, and in what concerns the equity premiums obtained from arithmetic returns of the S\&P 500, the point estimates range between $4.715104 \%$ and $10.99390 \%$. These point estimates are higher and less plausible than before. The reason why these estimates are higher is the fact that most of the included dummies in the regressions correspond to negative realizations of the equity premium. All average equity premiums are statistically significantly different from zero, with the lowest t-statistic being 2.751336 . As a consequence the $95 \%$ confidence interval of the equity premium of the regression pertaining to this t-statistic does not include negative realizations, contrary to previous evidence. This is probably due to the impossibility of applying an HAC standard error making the actual standard error understated and the actual t-statistic overstated. The minimum limit of the $95 \%$ confidence intervals of these eight specifications is an annualized $1.3562 \%$, while the maximum of the lowest limits of the same $95 \%$ confidence intervals is an annualized $5.7602 \%$. The maximum limit of all $95 \%$ confidence intervals is $16.2276 \%$, 
and the minimum of the upper limits of these intervals is $8.0740 \%$. There is also some variation in the standard errors. The minimum standard error is $1.7138 \%$ and the maximum is $3.1593 \%$.

Table 3. Actual p-values of the Ljung-Box Q-statistics for the lag length specified in parentheses.

\begin{tabular}{|c|c|c|c|c|}
\hline & \multicolumn{2}{|c|}{$1200 *\left(\left(s p 500_{t}-s p 500_{t-1}\right) / s p 500_{t-1}\right)-T B 3$} & \multicolumn{2}{|c|}{$1200 *\left(L N\left(s p 500_{t} / s p 500_{t-1}\right)\right)-T B 3$} \\
\hline & Without dummies & With dummies & Without dummies & With dummies \\
\hline \multicolumn{5}{|c|}{ Unconditional mean: } \\
\hline $\mathrm{Q}(3)$ & 0.245 & 0.706 & 0.166 & 0.625 \\
\hline $\mathrm{Q}(6)$ & 0.040 & 0.048 & 0.027 & 0.036 \\
\hline $\mathrm{Q}(12)$ & 0.192 & 0.184 & 0.151 & 0.150 \\
\hline $\mathrm{Q}(18)$ & 0.257 & 0.310 & 0.220 & 0.273 \\
\hline $\mathrm{Q}(24)$ & 0.367 & 0.375 & 0.324 & 0.338 \\
\hline \multicolumn{5}{|c|}{ EGARCH: } \\
\hline $\mathrm{Q}(3)$ & 0.663 & & 0.616 & \\
\hline $\mathrm{Q}(6)$ & 0.141 & & 0.136 & \\
\hline $\mathrm{Q}(12)$ & 0.506 & & 0.504 & \\
\hline $\mathrm{Q}(18)$ & 0.630 & & 0.642 & \\
\hline $\mathrm{Q}(24)$ & 0.676 & & 0.676 & \\
\hline \multicolumn{5}{|c|}{$\underline{\text { Robust least squares: }}$} \\
\hline $\mathrm{Q}(3)$ & 0.245 & 0.710 & 0.166 & 0.631 \\
\hline $\mathrm{Q}(6)$ & 0.040 & 0.049 & 0.027 & 0.037 \\
\hline $\mathrm{Q}(12)$ & 0.192 & 0.184 & 0.151 & 0.150 \\
\hline $\mathrm{Q}(18)$ & 0.257 & 0.311 & 0.220 & 0.274 \\
\hline $\mathrm{Q}(24)$ & 0.367 & 0.375 & 0.324 & 0.338 \\
\hline \multicolumn{5}{|c|}{ Quantile regression: } \\
\hline $\mathrm{Q}(3)$ & 0.245 & 0.716 & 0.166 & 0.640 \\
\hline $\mathrm{Q}(6)$ & 0.040 & 0.049 & 0.027 & 0.037 \\
\hline $\mathrm{Q}(12)$ & 0.192 & 0.184 & 0.151 & 0.150 \\
\hline $\mathrm{Q}(18)$ & 0.257 & 0.312 & 0.220 & 0.276 \\
\hline $\mathrm{Q}(24)$ & 0.367 & 0.375 & 0.324 & 0.338 \\
\hline \multicolumn{5}{|c|}{ Markov switching regressions } \\
\hline \multicolumn{5}{|c|}{ (same variances): } \\
\hline $\mathrm{Q}(3)$ & 0.201 & 0.424 & 0.197 & 0.437 \\
\hline $\mathrm{Q}(6)$ & 0.034 & 0.026 & 0.032 & 0.021 \\
\hline $\mathrm{Q}(12)$ & 0.196 & 0.139 & 0.193 & 0.121 \\
\hline $\mathrm{Q}(18)$ & 0.263 & 0.219 & 0.265 & 0.204 \\
\hline $\mathrm{Q}(24)$ & 0.384 & 0.290 & 0.381 & 0.279 \\
\hline \multicolumn{5}{|c|}{ Markov switching regressions } \\
\hline \multicolumn{5}{|c|}{ (different variances): } \\
\hline $\mathrm{Q}(3)$ & 0.504 & 0.651 & 0.486 & 0.643 \\
\hline $\mathrm{Q}(6)$ & 0.103 & 0.116 & 0.079 & 0.115 \\
\hline $\mathrm{Q}(12)$ & 0.442 & 0.298 & 0.380 & 0.295 \\
\hline $\mathrm{Q}(18)$ & 0.517 & 0.458 & 0.487 & 0.446 \\
\hline $\mathrm{Q}(24)$ & 0.557 & 0.564 & 0.540 & 0.533 \\
\hline
\end{tabular}

Notes: See notes under Table 1 and Table 2. Robust standard errors do not affect the actual p-values of the Q-statistics. The actual p-values of the Q-statistics for the two EGARCH models are on the standardized residuals.

In Table 2, and in what concerns the equity premiums obtained from geometric returns of the S\&P 500, the point estimates range more widely between $3.769370 \%$ and $11.64497 \%$. The latter point estimate is too high and less plausible. Since most of the included dummies in the regressions correspond to negative realizations of the equity premium, the estimates of the constant in the regressions are higher than in Table 1. All average equity premiums are statistically significantly different from zero, with the lowest t-statistic being 2.204516 . As in the previous paragraph, the $95 \%$ confidence interval of the equity premium of the regression pertaining to this t-statistic does not include negative realizations, contrary to previous evidence in Table 1. Again this is probably due to the impossibility of applying an HAC standard error making the actual standard error understated and the actual t-statistic overstated. The minimum limit of the $95 \%$ confidence intervals of all the eight specifications is an annualized $0.4181 \%$, which is very close to zero, while the maximum of the lowest limits of the same $95 \%$ confidence intervals is an annualized $6.6775 \%$. The maximum limit of all $95 \%$ confidence intervals is $16.6124 \%$, and the minimum of the upper limits of these intervals is $7.1207 \%$. There is little evidence that, after taking log returns, the estimates are $2 \%$ lower than 
those in the previous paragraph. Again there is also some variation in the standard errors. The minimum standard error is $1.7098 \%$ and the maximum is $3.0859 \%$.

An indicator of good specification is the absence of serial correlation in the residuals. Table 3 reports the actual p-values of the Ljung-Box Q-statistics for lag lengths of 3, 6, 12, 18, and 24 months. All Q-statistics are on the residuals except the Q-statistics on the EGARCH model which are on the standardized residuals. These are the residuals divided by the conditional standard deviations. The Q-statistics are not affected from estimation by robust standard errors. Hence there is no need to repeat the same p-values when robust standard errors are implemented. A vast majority of the p-values, close to unanimity, are above $5 \%$, even above $10 \%$, failing to reject the null of no serial correlation. However there is evidence that, when 6 months is chosen as the lag length, serial correlation becomes significant at the $5 \%$ marginal significance level but not at the $2 \%$ or $1 \%$ marginal significance levels. This should not come as a surprise, given the supremacy of the evidence for other lag lengths, and may be due to some kind of seasonality, or even just due to sampling error. Based on these Q-statistics all the models seem to be well specified. This implies that the $\tilde{X}_{j} \mathrm{~s}$ in equation (1) are non-existent or quite unstable for a market return, although they may be important for specific individual financial assets, and this renders the estimators efficient in addition to being unbiased and consistent.

\section{Conclusion}

This paper provides for unconditional estimators of the equity premium, obtained by the constants in regressions of the equity premium on a constant. More than one specification and more than one type of standard errors are implemented. The specifications include ordinary least squares, EGARCH, robust least squares, quantile regressions, and Markov switching regressions with two regimes. The analysis is repeated by adding in categorical variables that represent the outliers that are beyond plus or minus two standard errors of the estimates of the recursive residuals. All models are subjected to serial correlation tests on the residuals. These tests support the absence of serial correlation. Consequently the models are well specified and the estimators are not only unbiased and consistent but are also efficient. The paper gives point estimates and $95 \%$ confidence intervals of the equity premium, develops hypothesis tests, and reports point estimates of the standard errors. The results help in evaluating the magnitude of the equity premium and the precision with which this premium is measured. Hereafter are statistics on the equity premiums. For the regressions with the arithmetic percentage rate of the S\&P 500, the minimum of the lowest margins is $-0.1500 \%$, and the maximum of the lowest margins is $5.7602 \%$. For these same regressions the minimum of the highest margins is $7.9229 \%$ and the maximum of the highest margins is $15.1967 \%$. The point estimates are between $3.886473 \%$ and $10.99390 \%$. For the regressions with the geometric formulae of the S\&P 500, the minimum of the lowest margins is $-1.2836 \%$, and the maximum of the lowest margins is $6.6775 \%$. For these same regressions the minimum of the highest margins is $6.8997 \%$ and the maximum of the highest margins is $16.6124 \%$. The point estimates are between $2.808065 \%$ and $11.64497 \%$. The lowest standard error is $1.6215 \%$ and the highest is $3.1593 \%$. This compares with a standard error of $1.96 \%$ for the US in Dimson et al. (2008).

\section{References}

Arnott, R. D. \& Bernstein, P. L. (2002). What risk premium is "normal"? Financial Analysts Journal, 58, 2, 64-85. http://dx.doi.org/10.2469/faj.v58.n2.2524

Basset, G. Jr., \& Koenker, R. (1982). An empirical quantile function for linear models with i.i.d. errors. Journal of the American Statistical Association, 77, 378, 407-415. http://dx.doi.org/10.2307/2287261

Bollerslev, T., \& Wooldridge, J. M. (1992). Quasi-maximum likelihood estimation and inference in dynamic models with time varying covariances. Econometric Reviews, 11, 143-172. http://dx.doi.org/10.1080/07474939208800229

Bostock, P. (2004). The equity premium. The Journal of Portfolio Management, 30, 2, 104-111. http://dx.doi.org/10.3905/jpm.2004.319936

Dimson, E., Marsh, P. \& Staunton, M. (2008). The worldwide equity premium: a smaller puzzle. In Handbook of the equity risk premium, Mehra, R. (ed.), 467-504. http://dx.doi.org/10.1016/B978-044450899-7.50023-3

Easton, P. (2004). PE ratios, PEG ratios, and estimating the implied expected rate of return on equity capital. Accounting Review, 79, 73-95. http://dx.doi.org/10.2308/accr.2004.79.1.73

Easton, P., Taylor, G., Shroff, P., \& Sougiannis, T. (2002). Using forecasts of earnings to simultaneously estimate growth and the rate of return on equity investment. Journal of Accounting Research, 40, 657-676. http://dx.doi.org/10.1111/1475-679X.00066 
Fama, E., \& French, K. (2002). The equity premium. Journal of Finance, 57, 2, 637-659. http://dx.doi.org/10.1111/1540-6261.00437

Fitzgerald, T., Gray, S., Hall, J., \& Jeyaraj, R. (2013). Unconstrained estimates of the equity risk premium. Review of Accounting Studies, 18:560-639. http://dx.doi.org/10.1007/s11142-013-9225-z

Frühwirth-Schnatter, S. (2006). Finite mixture and Markov switching models. New York: Springer Science + Business Media LLC.

Goetzmann, W. N., \& Ibbotson, R. G. (2006). The equity risk premium, essays and explorations. New York: Oxford University Press.

Goldfeld, S. M., \& Quandt, R. E. ( 1973). A Markov model for switching regressions. Journal of Econometrics, 3-16. http://dx.doi.org/10.1016/0304-4076(73)90002-X

Goldfeld, S. M., \& Quandt, R. E. (1976). Studies in nonlinear estimation. Cambridge, MA: Ballinger.

Hamilton, J. D. (1990). Analysis of time series subject to changes in regime. Journal of Econometrics, 45, 39-70. http://dx.doi.org/10.1016/0304-4076(90)90093-9

Hamilton, J. D. (1994). Time series analysis. Princeton: Princeton University Press.

Huber, P. J. (1973). Robust regression: asymptotics, conjectures and Monte Carlo. The Annals of Statistics, 1, 5, 799-821. http://dx.doi.org/10.1214/aos/1176342503

Huber, P. J. (1981). Robust statistics. New York: John Wiley \& Sons. http://dx.doi.org/10.1002/0471725250

Koenker, R. (1994). Confidence intervals for regression quantiles. In Asymptotic statistics, Mandl, P. \& Huskova, H. (eds) New York: Springer-Verlag, 349-359. http://dx.doi.org/10.1007/978-3-642-57984-4_29

Koenker, R. (2005). Quantile regression. New York: Cambridge University Press. http://dx.doi.org/10.1017/CBO9780511754098

Koenker, R., \& Basset, G. Jr. (1978). Regression quantiles. Econometrica, 46, 1, 33-50. http://dx.doi.org/10.2307/1913643

Koenker, R. \& Machado, J. A. F. (1999). Goodness of fit and related inference processes for quantile regression. Journal of the American Statistical Association, 94, 448, 1296-1310. http://dx.doi.org/10.1080/01621459.1999.10473882

Lucas, R. E. Jr. (1978). Asset prices in an exchange economy. Economterica, 46, $1429-1445$. http://dx.doi.org/10.2307/1913837

Maddala, G. S. (1986). Disequilibrium, self-selection, and switching models. In Handbook of econometrics, Griliches, Z. \& Intriligator, M. D. (eds), Volume 3, Amsterdam: North-Holland.

Mehra, R. (ed) (2008). Handbook of the equity risk premium. Amsterdam: Elsevier. http://dx.doi.org/10.1016/B978-044450899-7.50006-3, http://dx.doi.org/10.1016/B978-044450899-7.50004-X

Mehra, R., \& Prescott, E. C. (1985). The equity premium: a puzzle. Journal of Monetary Economics, 15, $145-161$. http://dx.doi.org/10.1016/0304-3932(85)90061-3

Nekrasov, A., \& Ogneva, M. (2011). Using earnings forecasts to simultaneously estimate firm-specific cost of equity and long-term growth. Review of Accounting Studies, 16, 414-457. http://dx.doi.org/10.1007/s11142-011-9159-2

Nelson, D. B. (1991). Conditional heteroskedasticity in asset pricing: a new approach. Econometrica, 59, 347-370. http://dx.doi.org/10.2307/2938260

Newey, W. K., \& West, K. D. (1987). A Simple, positive semi-definite, heteroskedasticity and autocorrelation-consistent covariance matrix. Econometrica, 55, 703-708. http://dx.doi.org/10.2307/1913610

Ohlson, J. A. (1995). Earnings, book values and dividends in equity valuation. Contemporary Accounting Research, 11, 661-687. http://dx.doi.org/10.1111/j.1911-3846.1995.tb00461.x

Ross, S. (1976). The arbitrage theory of capital asset pricing. Journal of Economic Theory, 13, 341-360. http://dx.doi.org/10.1016/0022-0531(76)90046-6

Weil, P. (1989). The equity premium puzzle and the risk-free rate puzzle. Journal of Monetary Economics, 24, 401-421. http://dx.doi.org/10.1016/0304-3932(89)90028-7

Welch, I. (2000). Views of financial economists on the equity premium and on professional controversies. Journal of Business, 73, 4, 501-537. http://dx.doi.org/10.1086/209653 